\title{
Salutogenic Profile of Police Trainees on Entry into the Profession
}

\author{
Nomfusi Bekwa \\ Marié de Beer \\ University of South Africa
}

Address correspondence to Nomfusi Bekwa, Department of Industrial \& Organisational Psychology, University of South Africa, PO Box 392, Pretoria 0003, E-mail: bekwann@unisa.ac.za.

The study aimed to determine the salutogenic (wellbeing) profile of South African police trainees on entry into the profession. Participants were police trainees with an average age of 26 years enrolled for basic training in a police college. Sample sizes ranged between 275 and 499 depending on the questionnaire. The participants completed six questionnaires, namely Orientation to Life Questionnaire (Antonovsky, 1987) Locus of Control Inventory (Schepers, 1999), Self Efficacy Scale (Bandura, 1997), Personal Views Survey (Kobasa, 1979), Potency Scale (Ben-Sira, 1985) and the Self-Control Schedule (Rosenbaum, 1990). The results indicated the trainees' abilities in logical reasoning, determination, independence, confidence, self control and influence that could be resources to support their wellbeing. The police trainees scored above average on most of the constructs, thereby suggesting their readiness to deal with the stressful occupation they were being trained for. Furthermore, the police trainees demonstrated a comparable or more positive salutogenic profile than those obtained in other South African studies.

Keywords: salutogenic constructs, sense of coherence, locus of control, self efficacy, hardiness, potency, learned resourcefulness, police trainees

\section{Introduction}

Work is viewed as an element of human life that is important in the understanding of the self and the world in general (Coles, 2003). According to Crede and Price (2003), work becomes an extension of the self whereby people define themselves by what they do. The workplace thus becomes a vital part of self identification, social relationships, sense of purpose and enhancement of the self concept (Crede \& Price, 2003). In the case of policing, exposure to violence can be emotionally unsettling (Lennings, 1997), thus increasing the need for coping and the challenge to maintain wellbeing. However, some people thrive on stressful situations; they have stress resistant traits and can develop coping mechanisms to manage job and life demands in a health promoting manner (Strümpfer, 1990). This has led to an increase in the interest in salutogenesis (Strümpfer, 1990; Van Breda, 2001).

\section{Salutogenesis: Background and Definition}

According to Antonovsky (1984), salutogenesis set out to define health more broadly than simply just the absence of illness. Although it was not developed to replace the pathogenic paradigm (Antonovsky \& Bernstein, 1986), it can be seen as an alternative paradigm that focuses on the positive side of health (Van Breda, 2001). The word, salutogenesis, is from the Latin and Greek languages translated as health (salus) and origins (genesis), resulting in the literal translation of salutogenesis meaning the 'origins of health' (Strümpfer, 1990). It deals with the strengths individuals use to manage situations of tension and stress in their lives (Dhaniram \& Cilliers, 2004). Salutogenic functioning brings about the ability to maintain competence, mastery and the strength to embrace the challenges of life (Dass-Brailsford, 2005), the ability to bounce back (Caverly, 2005) and balancing life threatening circumstances with the strengths and protective traits within the individual (Van Breda, 2001). These are strengths and characteristics that can ensure coping and the optimal psychological functioning necessary for those preparing to pursue police careers (Kelly, 2005). Therefore salutogenesis is focused on health promoting constructs and the higher individuals score on these constructs the better the individuals will be in dealing with life challenges.

Salutogenic Constructs. Although sense of coherence was central to Antonovsky's paradigm and model (Antonovsky, 1998), other constructs have come to be recognised and accorded almost the same importance within the salutogenic paradigm (Strümpfer, 1990). The six salutogenic constructs used are: sense of coherence, locus of control, self-efficacy, hardiness, potency and learned resourcefulness.

Sense of coherence. Sense of coherence (SOC) is a personal paradigm that indicates individuals' overall view of the world and their life in it (Antonovsky, 1979). It is a set of fundamental beliefs (Strümpfer, 1990), therefore a way of life rather than a consequence of life. The three components, namely, comprehensibility, manageability and meaningfulness are seen as the core of SOC (Antonovsky, 1979, 1984, 1998). Comprehensibility is a cognitive dimension that indicates the degree to which individuals perceive situations that confront them as consistent, structured, clear and predictable (Antonovsky, 1984). After comprehending a situation, individuals have to manage it. Therefore, manageability is seen as the degree of individuals' conviction that they have enough of the required resources to deal with the situation (Antonovsky, 1984). Meaningfulness is the connection individuals make between the comprehensibility and manageability components and to feel motivated to face life's difficult situations as worthwhile challenges (Antonovsky, 1984). Within the work situation, employees with strong SOC can exercise control over their work more easily, thus leading to lower stress levels (Coetzee \& Rothmann, 1999) which would be an important characteristic within the policing profession. 
Locus of control. The locus of control construct is based on the belief that outcomes are either directly a result of personal factors (internal locus of control) or are caused by external factors outside of the individual's control (external locus of control) (Rotter, 1966). It has been found that internally focussed people make more effort to control their environments, take steps to improve their conditions and place greater value on skills and achievement reinforcements, whereas externally focussed people look outside themselves, they place more value on fate, luck, or others and they are seen as less involved in their environment (Coetzee, 2004; Robbins, 2001). According to Schaufeli and Enzmann (1998), externals are more likely to be emotionally exhausted with little sense of personal accomplishment as opposed to the strong sense of purpose felt by internals.

Self efficacy. Self efficacy was initiated by Bandura (1977) as a construct within the social cognitive theory based on the belief that people who believe in their capabilities produce the desired effects as a result of their own actions. People with high self efficacy function optimally, are initiators of change in their own lives and lives of others, they have more confidence in their abilities, therefore are more prepared to put in increased effort to overcome challenges (Maddux, 2002; Robbins, 2001).

Hardiness. Kobasa, Maddi and Courington (1981) traced studies of hardiness to existential personality theories and explain it as a trait that protects one against stressful life events and vulnerability to illness, thus leading to healthier adjustment. Hardiness comprises three components, namely, commitment, control and challenge. Commitment places important value on self, self in relationship with others and life (Kobasa, 1982). Control relates to a sense of power individuals feel over outcomes of events (Van Breda, 2001). Challenge is the belief that change rather than stability is the mode of life and that it provides opportunity for growth (Kosaka, 1996). Individuals do not just commit to these values, but tend to believe that their actions would lead to the expected outcomes (Kobasa et al., 1981).

Potency. Potency has been defined as the degree to which individuals experience confidence and commitment based on the belief of their own capacities and past experiences (Ben-Sira, 1985). Strümpfer (1990) defined potency as the mechanism that prevents the tension from a difficult situation resulting into a permanent lasting stress disorder. This means the power within the individual to cope and move on. Van Breda (2001) noted similarities between potency and Antonovsky's SOC as both high potency and high SOC individuals use their past experience of successful coping with stressful situations as a reference for their expectations to have control over future events.

Learned resourcefulness. Learned resourcefulness is a collection of cognitive skills and behaviours that individuals utilise to self regulate internal responses to ensure the resultant desired outcomes (Rosenbaum \& Ben-Ari, 1985). The skills and behaviours that are learned serve as the source of information that can be used in the future to control future behaviour, and to build confidence to deal with any similar situation (Coetzee \& Rothmann, 1999; Strümpfer, 1990).

From the discussion of the salutogenic constructs it is clear that they contribute in different ways to the overall wellbeing of individuals (De Beer \& Korf, 2004). The constructs bring about the salutogenic functioning that integrates cognitive characteristics such as facilitation of understanding and comprehension of life; affective characteristics such as positive self regard and self acceptance; motivational characteristics such as high level of task orientation, self control and effective evaluation; and interpersonal characteristics such as interdependence and intimate interpersonal relationships (Cilliers \& Coetzee, 2003).

\section{Police Work in Context}

Mofamere (2003) described the role of police as a combination of force and service, wherein police use punitive and deterrent measures to uphold the law, but client-oriented activities to prevent and minimise potential threats to social order. Hence there is a continuous challenge for police members to find a balance between being a protector of the public and an enforcer of law. In addition to the role dilemma, police are constantly faced with potential violence towards themselves and others (Altbeker, 2005; Mayhew, 2001; Violanti, 1997), over-extended job demands (De Beer \& Korf, 2004; Swanepoel \& Pienaar, 2004), and unclear power and/or authority boundaries (Decicco, 2000).

Research has also found the police environment to be prone to increased burnout symptoms such as exhaustion, negativity, cynicism and devaluation of self and others (Johnson, Todd \& Subramanian, 2005), post traumatic stress disorder (PTSD) (Jackson, 2003; Violanti, 1997), suicide ideation (Rothmann \& Van Rensburg, 2002; Rothmann \& Strijdom, 2002) suicide (Mabe, 2004; Rothmann and Van Rensburg, 2002), substance abuse (Padayachee \& Singh, 2003; Rothmann \& Van Rensburg, 2002) and job withdrawal (Leontaridi \& Ward, 2002; Plani, Bowley \& Goosen, 2003; Schonteich, 2003).

According to Rothmann and Van Rensburg (2002), the stability, growth and development of a country depends, inter alia, on a productive, motivated and healthy police service. Hence a study that considers the nature of the work and the environment of policing in relation to health and wellness is valuable to understanding optimal police functioning and would have important social relevance (Cross, 2004; Jones \& Kagee, 2005; Kelley, 2005).

Goal of the Study. The objective of the study was therefore to determine the salutogenic profile of the trainees on entry into the policing profession and to highlight any areas of concern as they enter this stressful occupation. In order to assess the levels of salutogenic functioning demonstrated by the trainees, their mean scores were compared to those obtained in other South African studies. The interrelationships between the measured salutogenic constructs were also investigated.

\section{Method}

Participants and setting. Participants in the study were South African police trainees in a police college with matric as a minimum educational qualification. The sample sizes ranged from 275 to 499 participants (depending on the questionnaire as depicted in Table 1). The reason for this variation in sample sizes was the fact that the questionnaires could not be administered to all respondents due to practical and logistical challenges such as time constraints, the routine activities of the College that could not be changed, and other unforeseen circumstances. The average age of the sample was 26.04 years with a standard deviation of 3.084. Race and gender demographics were found to be $80 \%$ for blacks, $12 \%$ for coloureds, $3 \%$ for Asians and $5 \%$ for whites, whereas there were $51 \%$ females as against $49 \%$ of males.

Measures. The instruments that were included, are generally accepted as measurements of general coping and psychological wellbeing, and are therefore relevant for salutogenic profiling (Cilliers \& Coetzee, 2003; De Beer \& Korf, 2004; Dhaniram 
\& Cilliers, 2004; Strümpfer, 1990). Data were collected on sense of coherence, locus of control, self-efficacy, hardiness, potency and learned resourcefulness.

Sense of coherence. The Antonovsky questionnaire, commonly known as the Orientation to Life Questionnaire (OLQ) or SOC scale, was used to measure SOC as a total score and also provided individual scores for its three components. Antonovsky (1984) reported alpha coefficients varying between 0.85 and 0.91 , and test-retest reliability ranging from 0.41 to 0.97. Cilliers and Coetzee (2003) cited various studies on the questionnaire as yielding internal consistencies ranging from 0.82 to 0.95 , construct validity ranging between 0.38 and 0.72 , and test-retest reliability of 0.54 . These results confirmed similar results obtained for reliability and validity in various South African studies.

Locus of control. The Locus of Control Inventory (LCI) (Schepers, 2005) was used to measure this construct. According to Schepers (2005), LCl comprises three scales namely, internal control, external control and autonomy. The internal control scale measures the extent to which individuals attribute their performance to forces within their control in terms of abilities and other personal characteristics, whereas the external control scale measures the extent to which the individuals attribute their performance to external forces such as luck and circumstances (Schepers, 2005). The autonomy scale refers to self-sufficiency where individuals are measured on whether they believe in themselves and can act independently with self confidence, decide and take action to solve problems (Schepers, 2005). According to Berg, Buys, Schaap and Olckers (2004), high reliability coefficients have been reported for the instrument with values of 0.88 for autonomy, 0.83 for internal LOC and 0.87 for external LOC. In his study, Schepers (2005) found alpha coefficients of 0.80 for autonomy, 0.77 for internal control and 0.81 for external control.

Self efficacy. The Self Efficacy Scale (Bandura, 1997) was developed to represent self appraisal of specific skills to control the environment (Shaw, 1999) and was initially used mostly for career and vocational development (Strauser, Ketz \& Keim, 2002). The Self Efficacy Scale is additive in nature and total scores represent individuals' levels of efficacy. Since the response format (from 1 to 7 ) attaches importance to the rating of 1 as positive, it means a low score on the questionnaire reflects a strong level of self efficacy. Conversely, a high score where an individual is inclined to answer closer to 7 would indicate low levels of self efficacy. Cilliers and Kossuth (2004) cited various studies which reported reliabilities between 0.71 and 0.86 . Cilliers and Ngokha (2006) also found the reliability coefficient in their study of university staff as equal to 0.71 .

Hardiness. The aim of the Personal Views Survey (PVS) is to measure the extent to which individuals believe in their ability to control events in their lives, the commitment they have to the activities in their lives, resistance to illness and the ability to anticipate change as a continually existing challenge (Kobasa, 1979). Reliability was reported to be at 0.85 for commitment, 0.68 for control and 0.70 for challenge (Kobasa, 1979). These findings on the hardiness construct have been found to be consistent in other research studies such as that of Cilliers and Ngokha (2006) who obtained almost similar values of Cronbach alpha at 0.74 for commitment, 0.74 for control and 0.70 for challenge.

Potency. The Potency Scale was developed by Ben-Sira (1985) as a measure of confidence that individuals have in their own capacities and those of the society which is perceived to be ordered, predictable and meaningful. The scale has two sections, the first consisting of 19 questions measuring self confidence, feelings of control, feelings of social obligation and perception of society. The second section has 15 questions related to diseases or illnesses typically diagnosed by a physician. The Cronbach alpha reliability of the scale for a study on marital quality among couples was 0.87 (Shamai \& Lev, 1999), whereas a study in a university environment yielded a reliability coefficient of 0.79 (Cilliers \& Ngokha, 2006).

Learned resourcefulness. The Self Control Schedule (SCS) was developed to assess individual tendencies to apply self control methods to solve behavioural problems (Rosenbaum, 1990). The reliability of the SCS ranges from 0.78 to 0.91 (Rosenbaum, 1988). In other studies it was found to be 0.96 for test-retest reliability after four weeks, with internal consistencies ranging from 0.78 to 0.86 (Coetzee \& Rothmann, 1999; Dhaniram \& Cilliers, 2004). Various studies cited by Dhaniram and Cilliers (2004) asserted the validity of the SCS through comparison with other existing scales such as Rotter's I-E scale, the $\mathrm{G}$ factor of the $16 \mathrm{PF}$ and self efficacy expectations. High correlations were obtained in all of these.

Procedure and Data Analysis. Permission for the study was granted as part of an ongoing research project in the South African police service. The participants were grouped according to their platoons and situated in different classrooms in the College. There were 10 test administrators (psychometrists and psychologists) who each took responsibility for a group. For all administrations standard introduction scripts were used explaining to the participants the aim of the project and the fact that the results would be used for research purposes only, and would therefore in no way affect them in their career. However, the need for them to perform and respond as honestly as they could to the questionnaires was stressed. There was also an outline of the programme for the sessions on how the test administration would take place.

The Statistical Program for Social Sciences (SPSS, 2005) was used to analyse the data, focussing specifically on descriptive profiles on the basis of the constructs (means \& standard deviations), establishing the reliability of the measuring instruments (Cronbach alpha coefficients) and the interrelationships between constructs (Pearson product-moment correlation coefficients). The statistical level of significance used was $p<0.01$ for 2-tailed tests. For the purpose of this study, $r$ values larger than 0.30 (medium effect size) were regarded as practically significant.

The practical significance of the differences between the observed means of the current study and those obtained in other South African studies, were also established using Cohen's d statistic. According to Thalheimer and Cook (2002), one of the advantages of Cohen's d effect size is that its calculation can enable researchers to make comparisons across large numbers of published studies. According to Cohen (1992) the following cut-off points for practical significance are applicable to differences between the means of groups $(d=0.2$ for a small effect; $d=0.5$ for a medium effect; $d=0.8$ for a large effect). For the purposes of this study d-values larger than 0.5 (medium effect) were regarded as practically significant.

\section{Results and Discussion}

The study is a by-product of a larger project in which a coping and resilience questionnaire was developed and standardised for use in the selection of trainees in the police service. 
Table 1. Descriptive Results of all Measurements

\begin{tabular}{|c|c|c|c|c|c|}
\hline Measuring instruments & $\mathrm{N}$ & Mean & SD & Cronbach alpha & Reliability evaluation \\
\hline $\mathrm{SOC}_{\text {total }}$ & 434 & 154.48 & 21.91 & .79 & High \\
\hline $\mathrm{SOC}_{\text {comprehensibility }}$ & 434 & 52.17 & 11.46 & .70 & Moderate \\
\hline $\mathrm{SOC}_{\text {manageability }}$ & 434 & 54.48 & 8.58 & .54 & Moderate \\
\hline $\mathrm{SOC}_{\text {meaningfulness }}$ & 434 & 47.64 & 7.12 & .58 & Moderate \\
\hline $\mathrm{LOC}_{\text {autonomy }}$ & 275 & 192.75 & 20.46 & .69 & Moderate \\
\hline $\mathrm{LOC}_{\text {internal }}$ & 275 & 170.19 & 17.00 & .81 & High \\
\hline $\mathrm{LOC}_{\text {external }}$ & 275 & 89.57 & 21.42 & .81 & High \\
\hline Self efficacy & 499 & 71.18 & 14.01 & .67 & Moderate \\
\hline Hardiness $_{\text {total }}$ & 410 & 93.90 & 14.55 & .82 & High \\
\hline Hardiness $_{\text {commitment }}$ & 410 & 33.57 & 5.75 & .66 & Moderate \\
\hline Hardiness $_{\text {control }}$ & 410 & 36.15 & 6.28 & .64 & Moderate \\
\hline Hardiness $_{\text {challenge }}$ & 410 & 23.39 & 5.81 & .57 & Moderate \\
\hline Potency total & 444 & 111.58 & 12.22 & .59 & Moderate \\
\hline Learned resourcefulness & 464 & 43.28 & 20.52 & .75 & High \\
\hline
\end{tabular}

The descriptive results are presented in Table 1 indicating the sample sizes, mean scores, standard deviations, Cronbach alphas and reliability interpretation.

Reliability. All the instruments used in this study (see Table 1) can be regarded as reliable with coefficients ranging from moderate to high, which is in line with 0.5 and 0.6 recommended by Nunnally (1978). The coefficients also correspond with research on the reliability of these instruments as reported in other studies by Cilliers and Coetzee (2003), Cilliers and Kossuth (2004) and Cilliers and Ngokha (2006).

Interrelationship between constructs. The interrelationships between the six constructs (Table 2) showed statistical and practical significance between most of the constructs, except Hardinesschallenge which yielded weaker correlations with most of the other constructs, specifically the weak correlations with LOCautonomy (0.10) and LOCinternal (0.02). This finding is contrary to what was expected of these three constructs.

Challenge entails the belief that change is the way of life and can be viewed as an opportunity for growth (Kosaka, 1996). Autonomy is about acting independently with confidence to correctly solve problems, whereas internal LOC is about the belief that whatever happens is within the person's control (Schepers, 2005). Based on these descriptions, one would expect the relationships between challenge and autonomy and internal LOC to be stronger, which was not the case in this study.

Salutogenic profile. The salutogenic profile depicted in Figure 1 is derived from the descriptive results indicated in Table 1. The profile was developed using the principles of the ordinal scale of measurement in which the levels have the property of magnitude, but no equal interval or absolute zero (Wolfaardt \& Roodt, 2005). The ordinal scale of measurement was selected for use as a simpler format of interpreting the profile as opposed to converting the scores into standardised scores.

Figure 1 illustrates that the police trainees scored average or above average in all the constructs, which indicates that the trainees would possibly be able to maintain competent functioning as they face major life stressors once they are in the field. The profile indicates the trainees as having insight into stressful situations and being able to put whatever comes their way into perspective (SOCtotal). With manageability the results show that the trainees are likely to possess confidence that they have the necessary resources to handle stressful situations (Antonovsky, 1984). In relation to meaningfulness, the results also indicate that the trainees are likely to find the balance between comprehensibility and manageability which can enable them to appraise difficult situations with effective coping and health enhancing behaviours. This is important for prospective police members who will, within the course of their profession, need to deal with the pressures of policing, such as violence and trauma, in a health embracing manner, as opposed to health endangering behaviours like substance abuse.

The results also indicate high scores of self efficacy, autonomy and internal LOC. This means that the trainees are likely to have confidence in their abilities to overcome challenges (Maddux, 2002), to take effort to control their environment and to place value on skills and achievement reinforcements (Robbins, 2001). However, it should be noted that self efficacy is task specific, which means that individuals may have high scores in one task and low scores in another. With autonomy and internal LOC being above average, the trainees are likely to be emotionally stable, free thinking, responsible, firm and analytical (Schepers, 2005). As a result of these constructs the trainees are likely to handle stressful situations with confidence.

Potency is about having confidence based on self belief and past experiences (Ben-Sira, 1985) which mean the trainees can most likely expect to overcome difficult situations confidently and successfully without developing lasting stress disorders. With the high score of learned resourcefulness, the police trainees would be likely to use their self control skills to control internal emotions and focus on problem solving strategies.

The results indicate that the police trainees have most of the constructs necessary to cope with the stressful conditions that are part and parcel of the policing profession. However, this should be viewed cautiously. The trainees in this study are at the initial stage of the policing career and, although they may have an idea of the circumstances within the profession, they have not experienced the reality of it as yet. As Rothmann and Van Rensburg (2002) found in their study, police members who had been working for a few years indicated a weaker SOC than trainees at a police training college.

Table 3 provides a comparison of the current study to other published studies based on various South African groups. The 


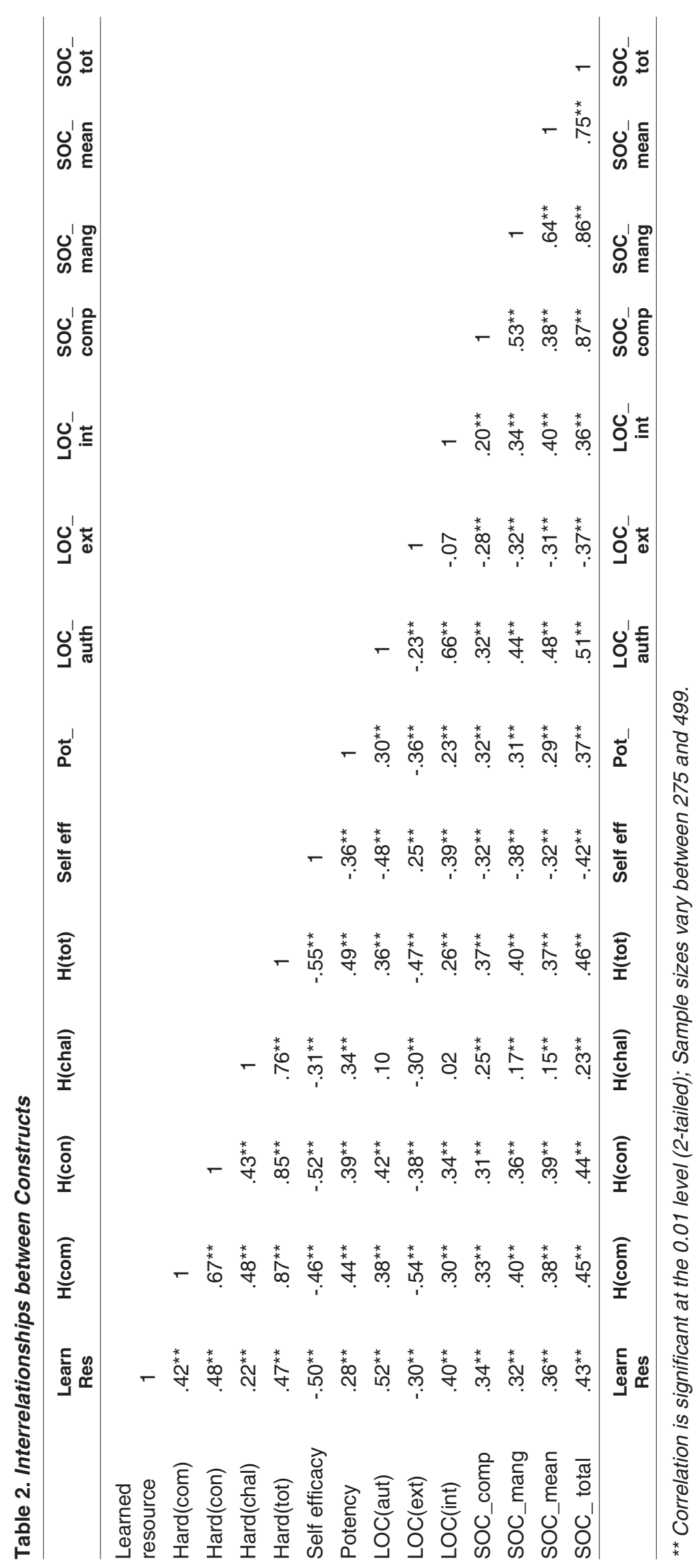




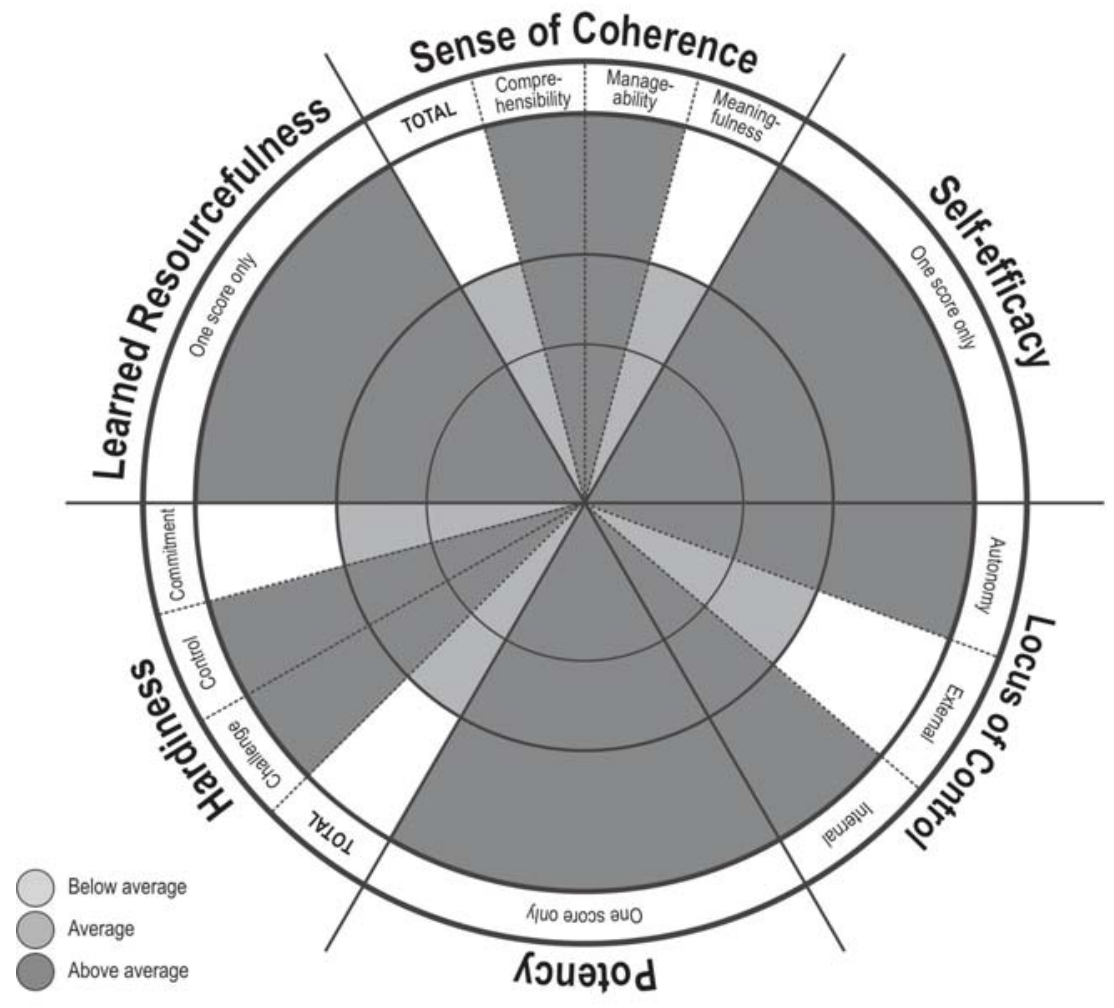

comparisons made were with studies of different groups such as second year students (Schaap et al., 2003), third year students (Barends, 2004), working mothers (Herbst, Coetzee \& Visser, 2007), employees from a financial institution head office (Gropp, Geldenhuys \& Visser, 2007), community service doctors (Dhaniram \& Cilliers, 2004), university administrative staff (Cilliers \& Ngokha, 2006), middle managers from a nature reserve organisation (Marais, 1997) and middle managers from a semi-governmental organisation (Cilliers \& Coetzee, 2003). In the study of Schaap et al. (2003) the second year student group was divided by race with group ${ }^{1}$ being Black students and group ${ }^{2}$ being White students. Study 1 in Table 3 refers to the results obtained in the current study.

From Table 3 it appears that the SOC constructs of police trainees were significantly stronger than the SOC constructs of working mothers, indicated by medium to large effect sizes. For employees from the financial institution there is no significant difference for comprehensibility and meaningfulness, whereas there was no practically significant difference with middle managers from the semi-governmental organisation. Differences indicated by medium effect sizes in favour of the police trainees were obtained for SOC total and manageability when compared to the employees from the financial institution.

There were no practically significant difference between the means of the external LOC and self efficacy of the police trainees and those of the comparison groups. In fact, the group of employees from the financial institution did not indicate any significant differences with the police trainees with regards to LOC. However, with regard to autonomy, the trainees obtained significantly higher means than the black and white second year stu- dent groups (large effect sizes) and also a higher mean than the black student group on internal LOC.

\section{Limitations and Recommendations}

A limiting factor to this research may have been the fact that the study was a by-product of another project and that the number of the measurements used may have fatigued the participants. It is also possible that test taking attitudes and response sets occurred, more so because the trainees knew that the results were for research purposes and would not influence their progress in the college or in their careers. A further study is needed to compare the profiles of police professionals at the different career stages to determine stability of the findings.

\section{Conclusion}

Except for the challenge construct, the police trainees demonstrated higher degrees of the hardiness constructs than the group of third year students from the study by Barends (2004). However when compared to middle managers from the nature reserve organisation the police trainees indicated significantly lower levels of the hardiness construct as a whole. The study (Marais, 1997) did not indicate the scores of the other three components of hardiness. With regard to potency, there was no practically significant difference between the means of potency of police trainees and that of middle managers from the nature reserve organisation. However, the police trainees indicated significantly lower levels of learned resourcefulness, represented by large effect sizes, than university administrative staff and community service doctors (Dhaniram \& Cilliers, 2004). 


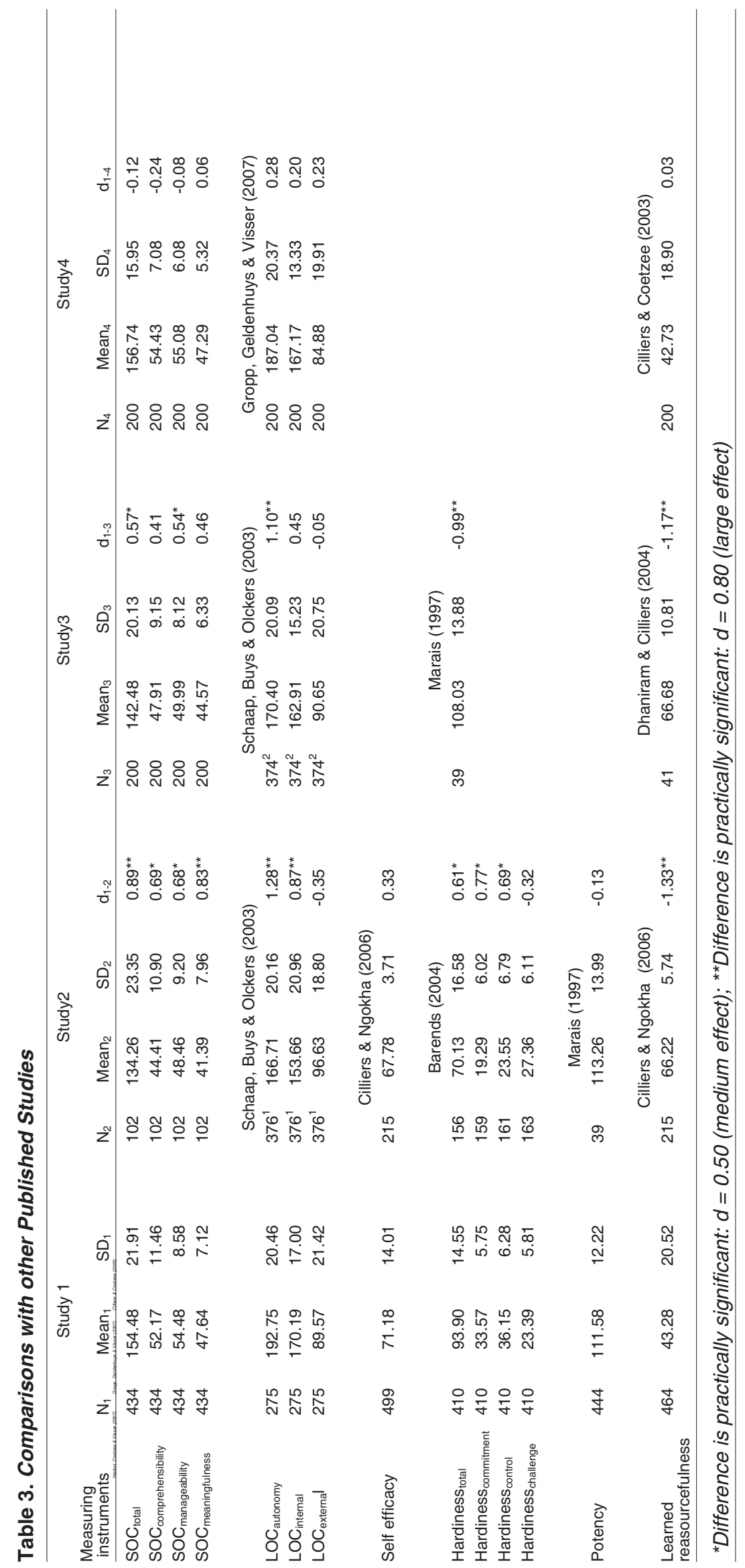


Overall, the results indicate that the police trainees demonstrated a comparable or more positive salutogenic profile than the comparison samples which should empower them to enter the policing environment with the resistance constructs necessary to affectively manage stress.

\section{References}

Altbeker, A. (2005). Positive trends: The $2004 / 5$ crime statistics. South African Crime Quarterly, 14, 1-10. Retrieved on May 182006 from www.iss.co.za.

Antonovsky, A. (1979). Health, stress and coping. San Francisco, CA: Jossey-Bass.

Antonovsky, A. (1984). The sense of coherence as a determinant of health. In J.D. Matarazzo, S.M. Weiss, J.A. Herd \& M.E. Miller (Eds), Behavioral health: $A$ handbook of health enhancement (pp. 114-129). New York: Wiley.

Antonovsky, A. (1987). Unravelling the mystery of health: How people manage stress and stay well. San Fransisco CA: Sage.

Antonovsky, A. (1998). The structure and properties of the sense of coherence scale. In H. I. McCubbin, E.A. Thompson, A.I. Thompson \& J.E. Fromer (Eds.), Stress, coping and health in families: Sense of coherence and resiliency (pp. 21-40). Thousand Oaks, CA: Sage.

Antonovsky, A., \& Bernstein, J. (1986). Pathogenesis and salutogenesis in war and other crises: Who studies the successful coper? In N.A. Milgram (Ed..), Stress and coping in time of war: Generalizations from the Israeli experience (pp. 52-65). New York: Brunner/Mazel.

Bandura, A. (1977). Self-efficacy: Toward a unifying theory of behavioural change. Psychological Review, 84, 191-215.

Bandura, A. (1997). Self-efficacy: The exercise of Control. New York: Freeman.

Barends, M.S. (2004). Overcoming adversity: An investigation of the role of resilience constructs in the relationship between socio-economic and demographic factors and academic coping. Unpublished masters dissertation. Bellville: University of the Western Cape.

Ben-Sira, Z. (1985). Potency: A stress-buffering link in the coping-stress-disease relationship. Social Science and Medicine, 21, 397-406.

Berg, A., Buys, M., Schaap, P., \& Olckers, C. (2004). The comparability of the construct validity of Schepers'locus of control inventory for first and second language respondents. South African Journal of Industrial Psychology, 30(3), 87-96.

Caverley, N. (2005). Civil service resiliency and coping. International Journal of Public Sector Management, 18(5), 401-413.

Cilliers, F \& Coetzee, S.C. (2003). The theoretical-empirical fit between three psychological wellness constructs: Sense of coherence, learned resourcefulness and self-actualisation. South African Journal of Labour Relations, Autumn, 4-24.

Cilliers, F., \& Kossuth, S.P. (2004). The reliability and factor structure of three measures of salutogenic functioning. South African Journal of Labour Relations, Winter, 59-76.

Cilliers, F., \& Ngokha, G. (2006). Confirmatory factor analysis on the measurement of five salutogenic constructs. Southern Africa Business Review, 10(1), 17-34.

Coe, R. (2002). It's the effect size, stupid: What effect size is and why it is important. Paper presented at the British Edu- cational Research Association annual conference, Exeter, 12-14 September, 2002.

Coetzee, S. (2004). Dispositional characteristics and the quality of work life of members of a self-managing work team. Paper presented at the $2^{\text {nd }}$ South African Work Wellness Conference at the North West University, Potchesfstroom, 24-26 March 2004.

Coetzee, S.C., \& Rothmann, S. (1999). Sense of coherence, learned resourcefulness and job satisfaction. Paper presented at the UIPsySAfrica Regional/PsySSA Conference, 18-23 July 1999.

Cohen, J. (1992). Quantitative methods in psychology: A power primer. Psychological Bulletin, 112(1), 155-159.

Coles, A. (2003). Counselling in the workplace. London: Open University Press.

Crede, M., \& Price, L. (2003). Negative self-regard at work: Frustrating the need for self-enhancement and self-consistency. South African Journal of Industrial Psychology, 29(3), 68-75.

Cross, C.L. (2004). Police trauma and addiction: Coping with the dangers of the job. The FBI Law Enforcement Bulletin. Retrieved on May 18, 2006 from http://findarticles.com .

Dass-Brailsford, P. (2005). Exploring resiliency: Academic achievement among disadvantaged black youth in South Africa. South African Journal of Psychology, 35(3), 574-591.

Dhaniram, N., \& Cilliers, F.V.N. (2004). Stress, burnout and salutogenic functioning amongst community service doctors in KwaZulu-Natal hospitals. Poster session presented at the $2^{\text {nd }}$ South African Work Wellness Conference at the North West University, Potchesfstroom, 24-26 March 2004.

De Beer, M., \& Korf, L. (2004). Developing of a new coping and resilience questionnaire. Paper presented at the $7^{\text {th }}$ Annual Industrial Psychology Conference (incorporating the psychometric conference) of the Society for Industrial and Organisational Psychology of South Africa at the CSIR, Pretoria, 23-25 June 2004.

Decicco, D.A. (2000). Police officer candidate assessment and selection. FBI Law Enforcement Bulletin, 69(12), 1-6.

Gropp, L., Geldenhuys, D., \& Visser, D. (2007). Psychological wellness constructs: Relationships and group differences. South African Journal of Industrial Psychology, 33(3), 24-34.

Herbst, L., Coetzee, S., \& Visser (2007). Personality, sense of coherence and the coping of working mothers. South African Journal of Psychology, 33(3), 57-67.

Jackson, C.A. (2003). A salutogenic approach to the management of critical incidents: An examinatgion of teachers 'stress responses and coping, and school management strategies and interventions. Unpublished thesis. Hawthorn, Victoria: Swinburne University of Technology.

Johnson, B.L., Todd, M., \& Subramanian, G. (2005). Violence in police families: Work-family spillover. Journal of Family Violence, 20(1), 3-12.

Jones, R., \& Kagee, A. (2005). Predictors of post-traumatic stress symptoms among South African police personnel. South African Journal of Psychology, 35(2), 209-224.

Kelley, T.M. (2005). Mental health and prospective police professionals. Policing: An International Journal of Police Strategies and Management, 28(1), 6-29.

Kobasa, S.C. (1979). Stressful life events, personality and health: An inquiry into hardiness. Journal of Personality and Social Psychology, 37(1), 1-11. 
Kobasa, S.C. (1982). The hardy personality: Toward a socia psychology of stress and health. In G.S. Sanders \& J. Suls (Eds.), Social Psychology of Health and IIIness (pp. 3-32). Hillsdale: Erlbaum.

Kobasa, S.C., Maddi, S.R., \& Courington, S. (1981). Personality and constitution as mediators in the stress-illness relationship. Journal of Health and Social Behaviour, 22, 368-398.

Kosaka, M. (1996). Relationship between hardiness and psychological stress response. Journal of Performance Studies, 3, 35-40.

Lennings, C.J. (1997). Police and occupationally related violence: A review. Policing: An International Journal of Police Strategies and Management, 20(3), 555-566.

Leontaridi, R.M., \& Ward, M.E. (2002). Work-related stress, quitting intentions and absenteeism. Discussion paper series, discussion paper no. 493. Institute for the Study of Labor.

Mabe, S.E. (2004). Perceptions of personnel on police suicide and the role of a chaplain. Unpublished masters dissertation. Pretoria: University of South Africa.

Maddux, J.E. (2002). Self-efficacy: The power of believing you can. In C.R. Synder \& S.J. Lopez (Eds), Handbook of positive psychology (pp.277-287). New York: Oxford University Press.

Marais, C.P. (1997). Salutogenesis as a paradigm in change management. Unpublished masters thesis. Pretoria: University of South Africa.

Mayhew, C. (2001). Occupational health and safety risks faced by police officers. Australian Institute of Criminology: Trends and Issues in Crime and Criminology Journal, 196, 1-6.

Mofamere, T.J. (2003). Managing cultural diversity in the South African police service (Gauteng Province): The role of a chaplain. Unpublished doctoral thesis. Pretoria: University of South Africa.

Nunnally, J.C. (1978). Psychometric theory. New York: McGraw-Hill.

Padayachee, A., \& Singh, D. (2003). Intimate violence and substance (ab)use: The correlative relationship. Acta Criminologica, 16(1), 108-114.

Plani, F., Bowley, D.M., \& Goosen, J. (2003). Death and injury on duty: A study of South African police officers. South African Medical Journal, 93, 851-853.

Robbins, S.P. (2001). Organizational behaviour (9th ed.). Englewood Cliff, NJ: Prentice-Hall.

Rosenbaum, M. (1988). Learned resourcefulness, stress and self-regulation. In S. Fisher \& J. Reason (Eds.), Handbook of life-stress, cognition and health (pp.483-496). Chichester: Wiley.

Rosenbaum, M. (1990). Learned resourcefulness: On coping skills, self control and adaptive behaviour. New York: Springer.

Rosenbaum, M., \& Ben-Ari, K. (1985). Learned helplessness and learned resourcefulness: Effects of noncontingent success. Journal of Personality and Social Psychology, 48(1), 198-215.

Rothmann, S., \& Strijdom, G. (2002). Suicide ideation in the South African police services in the North West province. South African Journal of Industrial Psychology, 28(1), 44-48.

Rothmann, S., \& Van Rensburg, P. (2002). Psychological strengths, coping and suicide ideation in the South African police services in the North West province. South African Journal of Industrial Psychology, 28(3), 39-49.
Rotter, J. (1966). Generalized expectations for internal versus external control of reinforcements. Psychological Monographs: General and Applied, 80(1), 1-28.

Schaap, P., Buys, M.A., \& Olckers, C. (2003). The construct validity of Schepers's locus of control inventory for black and white tertiary students. South African of Industrial Psychology, 29(1), 32-43.

Schaufeli, W.B., \& Enzmann, D. (1998). The burnout companion to study and practice. Philadelphia: Taylor \& Francis.

Schepers, J.M. (1999). Die Lokus van Beheer-vraelys: Konstruksie en evaluering van 'n nuwe meetinstrument. Unpublished Report: Rand Afrikaans University.

Schepers, J.M. (2005). The construction of a normative scale of locus of control. South African Journal of Industrial Psychology, 31(3), 1-11.

Schonteich, M. (2003). A bleak outlook: HIV/AIDS and the South African police service.South African Crime Quarterly, 5. Retrieved on May 162006 from the http://www.iss.co. za/pubs/CrimeQ/ No.5/1Aids.html.

Shamai, M., \& Lev, R. (1999). Marital quality among couples living under the threat of forced relocation: The case of families in the Golan Heights. Journal of Marital and Family Therapy, April. Retrieved on May 162006 from http://findarticles.com

Shaw, C. (1999). A framework for the study of coping, illness behaviour and outcomes. Journal of Advanced Nursing, 29(5), 1246-1256.

Statistical Package for the Social Sciences. (2005). Statistical Programs for Social Sciences (SPSS): Version 14.0. SPSS Inc.

Strauser, D.R., Ketz, K., \& Keim, J. (2002). The relationship between self-efficacy, locus of control and work personality. Journal of Rehabilitation, 68(1), 20-26.

Strümpfer, D.J.W. (1990). Salutogenesis: A new paradigm. South African Journal of Psychology, 20(4), 264-276.

Swanepoel, C., \& Pienaar, J. (2004). Coping, stress and suicide ideation in the South African police service in Gauteng province. Acta Criminologica, 17(2), 17-33.

Thalheimer, W., \& Cook, S. (2002). How to calculate effect sizes from published research articles: $A$ simplified methodology. Retrieved on May 11, 2009 from http://work-learning.com/effect_sizes.htm.

Van Breda, A.D. (2001). Resilience theory: A literature review. Unpublished manuscript. South African Military Health Service, Military Psychological Institute: Social Work Research and Development. Pretoria: South Africa.

Violanti, J.M. (1997). Suicide and the police role: A psychosocial model. Policing: An International Journal of Police Strategy and Management, 20(4), 698-715.

Wolfaardt, J.B., \& Roodt, G. (2005). Basic concepts. In C. Foxcroft \& G. Roodt (Eds), An introduction to psychological assessment in the South African context (2nd ed.). (pp. 24-45). Cape Town: Oxford University Press.

\section{Acknowledgements}

This article was based on the masters thesis: Bekwa, N.N. (2006). Salutogenic constructs of trainees working in a highly stressful occupation. Unpublished masters Thesis. Pretoria: University of South Africa. Also presented as poster: Bekwa, N. $\&$ De Beer, M. (2008). Salutogenic profile of police trainees on entry into the profession. Poster session presented at the British Psychological Society annual conference in Dublin, 2-4 April 2008. 
